LA W RENCE LIVERMORE NATIONAL LABORATORY

\section{Ablative Richtmyer-Meshkov Experiments}

V. Smalyuk, D. Martinez

October 5, 2012 
This document was prepared as an account of work sponsored by an agency of the United States government. Neither the United States government nor Lawrence Livermore National Security, LLC, nor any of their employees makes any warranty, expressed or implied, or assumes any legal liability or responsibility for the accuracy, completeness, or usefulness of any information, apparatus, product, or process disclosed, or represents that its use would not infringe privately owned rights. Reference herein to any specific commercial product, process, or service by trade name, trademark, manufacturer, or otherwise does not necessarily constitute or imply its endorsement, recommendation, or favoring by the United States government or Lawrence Livermore National Security, LLC. The views and opinions of authors expressed herein do not necessarily state or reflect those of the United States government or Lawrence Livermore National Security, LLC, and shall not be used for advertising or product endorsement purposes.

This work performed under the auspices of the U.S. Department of Energy by Lawrence Livermore National Laboratory under Contract DE-AC52-07NA27344. 


\section{Ablative Richtmyer-Meshkov Experiments \\ V. Smalyuk and D. Martinez \\ Lawrence Livermore National Laboratory}

Figure 1 shows a schematic of experimental setup for nonlinear Richtmyer-Meshkov (RM) instability experiments on OMEGA. Planar 15, 30, and 50- $\mu$ m-thick $\mathrm{CH}$ targets were driven with three UV beams using a 6-ns square pulse shape, total energy of $\sim 0.7 \mathrm{~kJ}$, and laser intensity of $\sim 5 \times 10^{13} \mathrm{~W} / \mathrm{cm}^{2}$. Initial target modulations were imposed by laser imprinting using a beam with a special 2D phase plate with modulation wavelength of $\sim 70$ microns. The timing of this beam was advanced by $\sim 200$ ps, relative to other drive beams that have regular SG distributed phase plates (DPP's). Figure 2 shows laser beam images, with SG4 DPP [Fig. 2(a)], and with a special 2D DPP [Fig. 2(b)]. Growth of target modulations was measured with x-ray radiography using uranium $(\sim 1.3 \mathrm{keV})$, samarium $(\sim 1.8 \mathrm{keV})$, and tantalum $(\sim 2.2 \mathrm{keV})$ backlighters on a framing camera with $10-\mu \mathrm{m}$ spatial resolution and 80 -ps temporal resolution. Backlighter targets were driven with 2-ns square pulse shape and intensity of $\sim 3 \times 10^{14} \mathrm{~W} / \mathrm{cm}^{2}$ using seven additional UV beams. Figure 3 shows an example of measured image at $1.1 \mathrm{~ns}$ (near the end of RM phase) taken with 50- $\mu$ m thick $\mathrm{CH}$ foil and tantalum backlighter. Evolution of 2D broadband modulations was observed in RM phase for all target types during a shock transit time before beginning of acceleration and subsequent RT growth. Figure 4 summarizes areal-density evolution of $2 \mathrm{D}$ modulation at wavelength of $70 \mu \mathrm{m}$ for $30-\mu \mathrm{m}$ and $50-\mu \mathrm{m}$ thick foils and compares data with predictions of 2D hydro code DRACO. Vertical dashed lines show expected times at the end of RM phase and beginning of the RT phase for these types of foils. Blue data points and curves correspond to 30- $\mu \mathrm{m}$ thick foils, while black curves and data points are for 50- 
$\mu$ m-thick foils. Areal density modulations grow throughout RM phase, their evolution is similar to code predictions, validating the simulations.

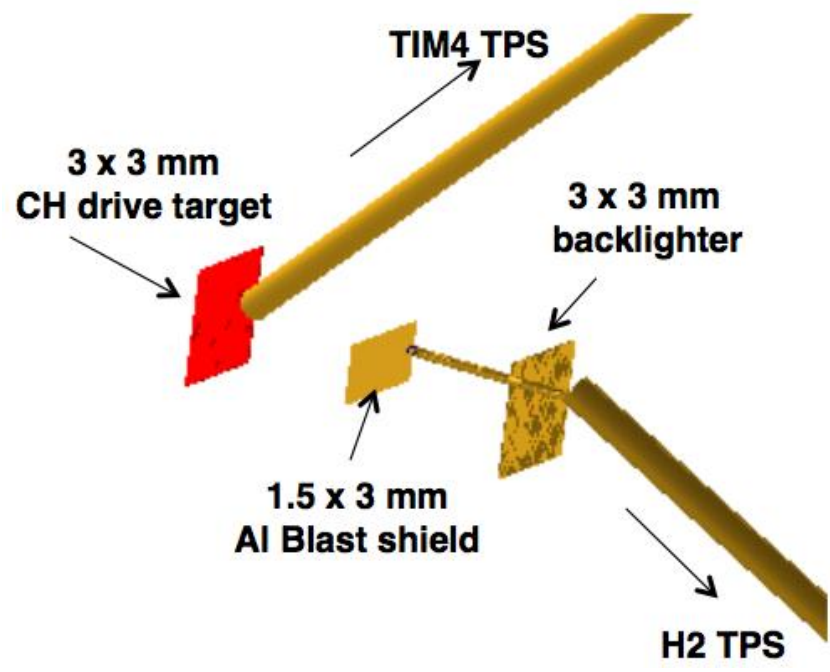

Figure 1: Experimental setup
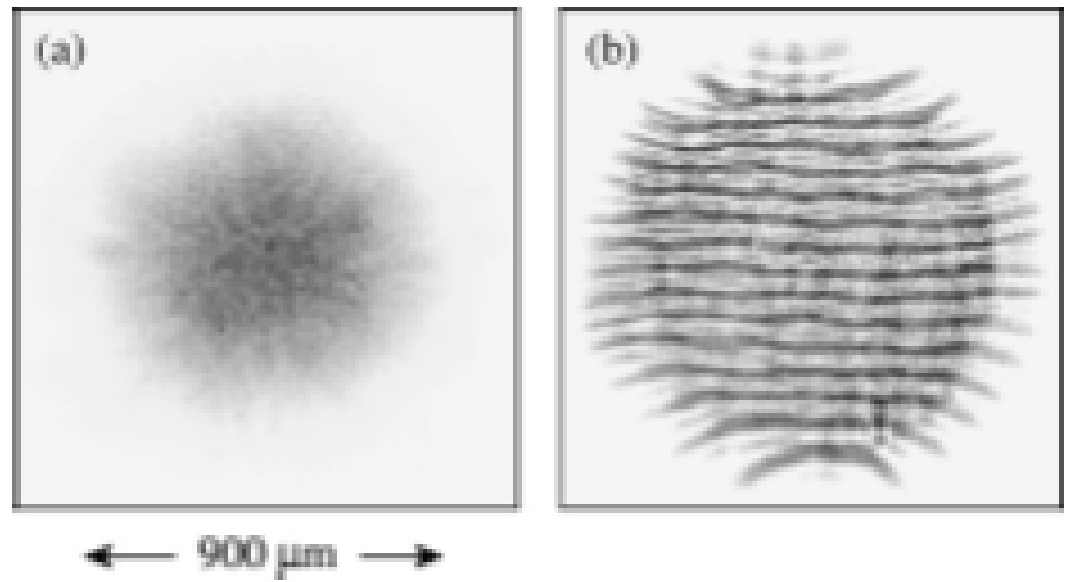

Figure 2: Laser beam images with (a) regular SG4 DPP, and (b) special 2D DPP. 


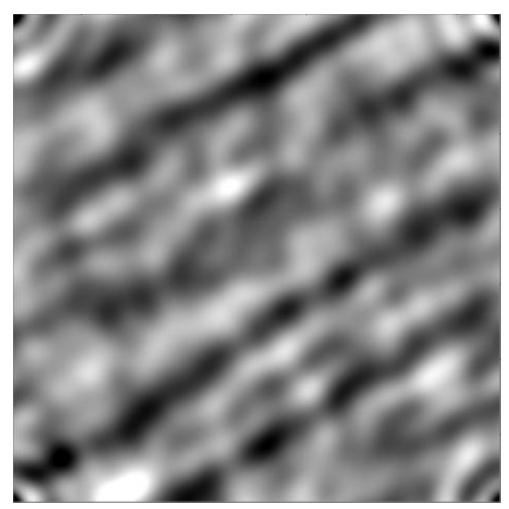

Figure 3: X-ray images of 2D broadband modulations near the end the Richtmyer-Meshkov instability growth phase measured in $50-\mu \mathrm{m}$ thick $\mathrm{CH}$ targets. 


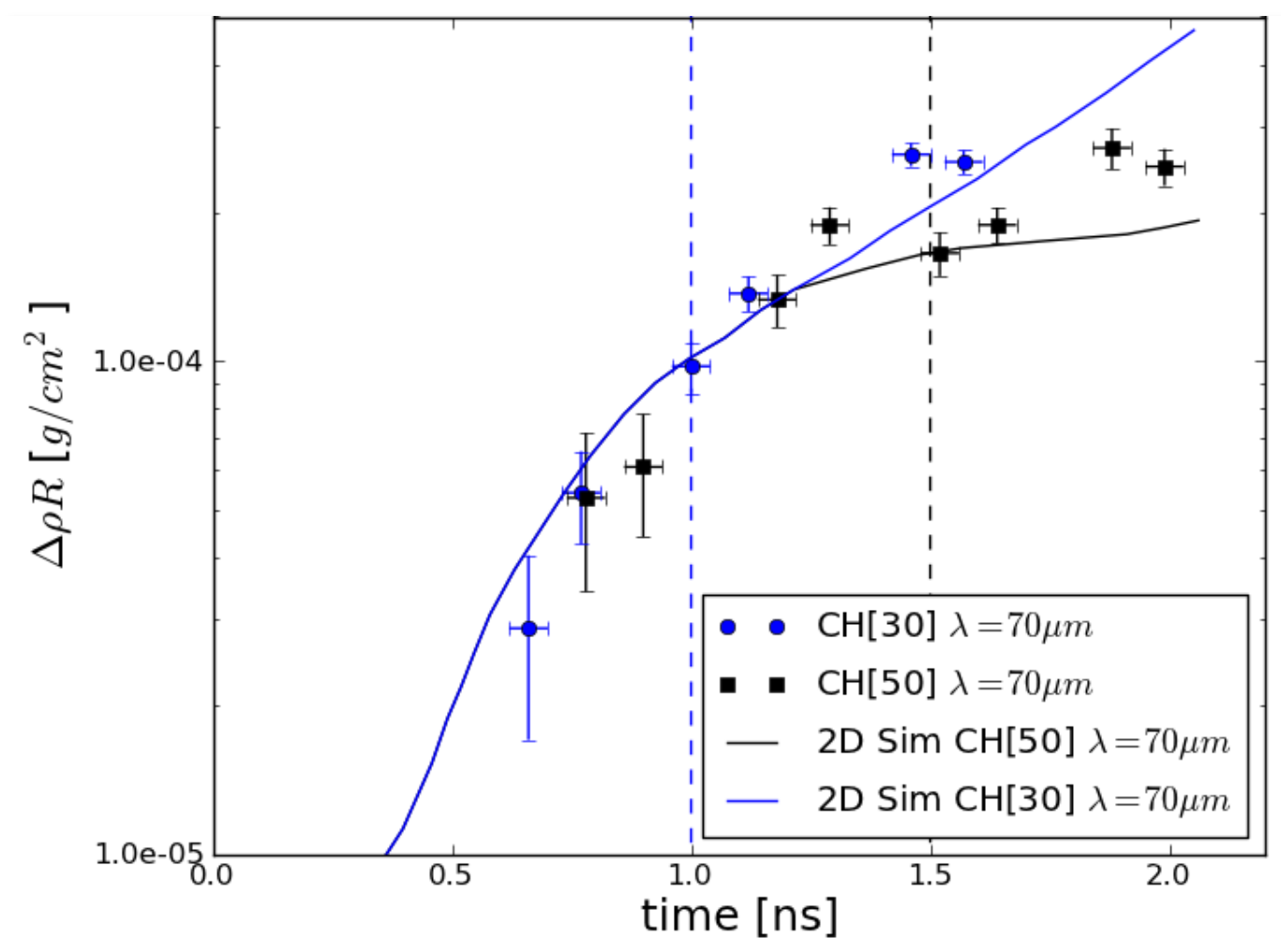

Figure 4: Evolution of 2D, areal-density modulations at wavelength of $70 \mu \mathrm{m}$ measured in 30$\mu \mathrm{m}$ thick foils (blue circles) and in $50-\mu \mathrm{m}$ thick foils (black squares). Solid curves correspond to 2D DRACO simulations, while dashed vertical curves correspond to times of the end of RM phase and beginning of RT phase in 30-um thick foils (blue curves) and 50-um thick foils (black curves).

This work was performed under the auspices of the U.S. Department of Energy by Lawrence Livermore National Laboratory under Contract DE-AC52-07NA27344. 